\title{
Effects of a 3-Week Inpatient Multidisciplinary Body Weight Reduction Program on Body Composition and Physical Capabilities in Adolescents and Adults with Obesity.
}

\author{
Stefano Lazzer \\ University of Udine: Universita degli Studi di Udine \\ Mattia D'Alleva ( $\nabla$ dalleva.mattia@spes.uniud.it) \\ università di Udine https://orcid.org/0000-0001-9179-1618 \\ Filippo Vaccari \\ University of Udine: Universita degli Studi di Udine \\ Gabriella Tringali \\ Experimental Laboratory for Auxo-Endocrinological Research, Istituto Auxologico Italiano, IRCSS \\ Roberta De Micheli \\ Experimental Laboratory for Auxo-Endocrinological Research, Istituto Auxologico Italiano, IRCCS \\ Alessandro Sartorio \\ Experimental Laboratory for Auxo-Endocrinologica Research, Istituto Auxologico Italiano, IRCCS
}

\section{Research}

Keywords: Physical capabilities, body composition, metabolic rehabilitation, adolescents, adults, obesity, physical activity.

Posted Date: November 19th, 2021

DOI: https://doi.org/10.21203/rs.3.rs-978419/v1

License: (9) (i) This work is licensed under a Creative Commons Attribution 4.0 International License. Read Full License

Version of Record: A version of this preprint was published at Frontiers in Nutrition on March 31st, 2022. See the published version at https://doi.org/10.3389/fnut.2022.840018. 


\section{Abstract \\ Background}

The aim of the present study was to examine the short-term changes in body composition and physical capabilities in subjects with obesity during a multidisciplinary inpatient body weight reduction program (BWRP).

\section{Methods}

One hundred thirty-nine adolescents (56 boys and 83 girls; BMI: $37.1 \pm 6.5 \mathrm{~kg} / \mathrm{m}^{2}$; Fat Mass, FM: $45.3 \pm 7.2 \%$ ) and 71 adults (27 males and 44 females; BMI: $44 \pm 4.7 \mathrm{~kg} / \mathrm{m}^{2}$; FM: $51.4 \pm 4.7 \%$ ) followed a 3-week inpatient BWRP consisting of regular physical activity, moderate energy restriction, nutritional education and psychological counseling. Before (T0) and after the end of the BWRP (T21), body composition was assessed with an impedancemeter, lower limb muscle power with Margaria Stair Climbing Test (SCT), lower limb functionality with Short Physical Performance Battery (SPPB) and the capacity of performing activity of daily living (ADL) with Physical Performance Test (PPT).

\section{Results}

At T21, obese adolescents showed a $4 \%$ reduction in body mass (BM) $(p<0.001)$, associated with a FM $(\mathrm{kg})$ reduction in boys $(-10 \%)$ and girls $(-6 \%)(p<0.001)$ and with a $3 \%$ reduction in fat-free mass (FFM, kg) recorded only in boys $(p=0.013)$. Obese adults showed a $5 \%$ BM reduction ( $p<0.001)$, associated with a $2 \% \mathrm{FFM}(\mathrm{kg})$ reduction $(\mathrm{p}<0.001)$ and a reduction of $9 \% \mathrm{FM}$ $(\mathrm{kg})$ in males and $7 \%$ in females $(\mathrm{p}<0.001)$. Regarding physical capabilities, at T21 in obese adolescents, PPT score increased by 4\% ( $<<0.001$ ), SCT (s) decreased by 5\% (boys) and 7\% (girls) ( $<0.001$ ), while SPPB score did not significantly change. In obese adults at T21, PPT score increased by $9 \%(p<0.001)$, SCT (s) decreased by 16\% $(p<0.001)$ only in females, and SPPB score increased by $\sim 7 \%$ (males) and $~ 10 \%$ (females) $(p<0.01)$.

\section{Conclusions}

In conclusion, moderate energy restriction and regular physical activity determine a 4-5\% BM reduction during a 3-week inpatient BWRP, improve physical capabilities and induce beneficial changes in body composition in adolescents and adults with obesity.

\section{Trial registration:}

This study was was approved by the Ethical Committee of the Istituto Auxologico Italiano (Milan, Italy; research code: 01C124; acronym: PRORIPONATFIS). Registered 11 November 2020 - Retrospectively registered.

\section{Introduction}

Over the past two decades, obesity has tripled in both children and adults in industrialized countries [1, 2], mainly due to the excess food-intake combined with an increase in time spent in sedentary activities, leading to a decrease in physical activity level [3-5]. Evidence suggests that major health consequences associated with obesity include hypertension [6-8], type 2 diabetes, cardiovascular disease [9], certain types of cancer and psychosocial complications [9]. In addition, previous studies have shown that subjects with obesity have lower aerobic and anaerobic capacities than their normal-weight counterparts [11-13], as well as higher perceived difficulty in performing physical exercise and activities of daily living (ADL) [14-17]. In agreement with these findings, other authors showed a reduction in maximal lower limb muscle power output and lower limb 
functionality in obese adolescents $[18,19]$ and adults $[14,15,17,20-23]$. In contrast, adolescents and adults with obesity were not found to be impaired in tasks requiring static balance [24, 25], though this finding is still debated [26, 27].

In obese subjects, short-term multidisciplinary inpatient body weight-reduction programs (BWRP) that include moderateintensity training, energy-restricted diets, and changes in food and behavioural habits have been reported to promote weight loss, reduce fat mass (FM) $[19,28,29]$ and improving both lower limb muscle power and functionality $[19,28,29]$ with a positive effects also on metabolic and cardiovascular risk profiles [30, 31].

Therefore, the aim of the present study was to determine whether a short-term (3-week) multidisciplinary BWRP in a third-level institution for the treatment of severe obesity, which includes physical activity, moderate energy restriction, nutrition education, and psychological counselling, can positively affect body composition, blood pressure (BP), lower limb muscle power and functionality, and capacity of performing ADL in adolescents and adults with obesity.

\section{Material And Methods}

\section{Subjects}

One hundred thirty-nine adolescents (56 boys and 83 girls, age range: 13-17 y) and 71 adults (27 males and 44 females, age range: 35-68 y) with obesity, participated in this study. Among adolescents, BMls for gender and chronological age were above the 99th percentile [32], while for adults the BMls were above $35 \mathrm{~kg} / \mathrm{m}^{2}$. Subjects were recruited as inpatients from the Division of Auxology (subjects aged < $18 \mathrm{y}$ ) and from the Division of Metabolic Diseases (subjects aged $>18 \mathrm{y}$ ), Istituto Auxologico Italiano, IRCCS, Piancavallo (VB) Italy. Before admission to the hospital for BWRP, none of the subjects had engaged in structured physical activity (i.e., regular activity of more than $60 \mathrm{~min} /$ week). All subjects had a complete medical history and physical examination. None of the adolescents or adults with obesity had signs or symptoms indicative of serious cardiovascular, respiratory, or orthopaedic disease that could significantly interfere with the functional test used in the study.

\section{Study Protocol}

The study was approved by the Ethical Committee of the Istituto Auxologico Italiano (Milan, Italy, research code: 01C124, acronym: PRORIPONATFIS) and was in accordance with the Declaration of Helsinki 1975, as revised in 2008. For adolescents, the protocol was explained to parents and written informed consent was obtained from parents or legal representatives. Patients aged $\geq 18$ gave written informed consent to participate in the study. Patients were hospitalized for a period of 3 weeks in the Division of Auxology (patients $<18 \mathrm{y}$ ) or in the Division of Metabolic Diseases (patients > $18 \mathrm{y}$ ), Istituto Auxologico Italiano, IRCCS, Piancavallo (VB). They followed a 3-week personalized BWRP consisting of lifestyle and physical activity, nutrition education, and psychological counselling. Full testing sessions were conducted at the beginning (TO) and at completion of the 3-week BWRP (T21). Testing session included assessment of anthropometric characteristics, body composition, blood pressure (BP), lower limb muscle power, lower limb functionality, and ability to perform ADL (see below for detailed description).

\section{Physical Activity}

The physical activity program consisted of 5 training days per week, under the supervision of a physical trainer. Each training session included: (i) 45-60 min per day of aerobic activities (walking on a treadmill or cycling on an ergometer) under heart rate monitoring (HR) and medical supervision (ii) 5-7 min of stretching before and after training. The intensity of aerobic activities was set at heart rate (HR) corresponding to 60 and $80 \%$ of the individual maximal HR estimated as 220-age (year). The research assistant and the physical trainers verified that each subject participated in each training session, performed the exercises correctly, and completed at least $95 \%$ of the exercise session and program.In addition, subjects had $1 \mathrm{~h} /$ day of aerobic leisure activities at the institution on Saturday and Sunday.

\section{Diet and Nutritional Education}


A Mediterranean diet was prescribed based on the initial basal metabolic rate test and physical activity level for each patients, and the amount of energy to be given with diet was calculated by subtracting approximately $\sim 25 \%$ from the estimated daily energy expenditure. In terms of macronutrients, the diet contained $21 \%$ proteins, $53 \%$ carbohydrates, and $26 \%$ lipids. The diet composition was formulated according to the Italian recommended daily allowance [33]. Each patient was free to choose foods from a heterogeneous daily menu, although five daily servings of fruits and vegetables were mandatory. Foods to which the patient reported allergic reactions were eliminated from the menu. A fluid intake of at least $1.5 \mathrm{l} /$ day was encouraged. In addition, the dietitian team checked that each subject had eaten every meal. On each day of the BWRP, the patients had dietetics classes consisting of lectures, demonstrations, and group discussions with and without a supervisor.

\section{Psychological counselling}

Cognitive-behavioural therapy strategies, such as stimulus control procedures, problem-solving and stress management training, development of healthy eating habits, assertiveness and social skills training, cognitive restructuring of negative maladaptive thoughts, and relapse prevention training, were chosen for the psychological sessions, which were conducted by a clinical psychologist 2-3 times per week in individual or group sessions. When possible (1 day per week), additional sessions were also conducted with patients' parents aimed at improving motivation for lifestyle change and interpersonal communication.

\section{Measurements}

\section{Physical characteristics and body composition}

Medical history was obtained and a baseline physical examination was performed. Stature and body mass (BM) were measured using a Harpenden stadiometer (Holtain Ltd., UK), and an electronic scale (Selus, Italy), respectively, with the subject wearing only light underwear. BMI $\left(\mathrm{kg} / \mathrm{m}^{2}\right)$ was calculated. The standard deviation score (SDS) of BMI-SDS was calculated using the LMS method [32] on Italian reference values for children and adolescents [34]. Body composition was measured using a multifrequency tetrapolar impedancemeter (BIA, Human-IM Scan, DS-Medigroup, Milan, Italy) with a delivered current of $800 \mu \mathrm{A}$ at a frequency of $50 \mathrm{kHz}$. To reduce measurement errors, care was taken to standardise the variables that affect the validity, reproducibility and precision of the measurement. Measurements were performed according to the method of Lukaski et al. ([35] (after 20 min of rest in the supine position with arms and legs relaxed and without contact with other parts of the body) and under strictly controlled conditions according to NIH guidelines [36] All females were studied outside of the menstrual period in order to avoid any possible influence on fluid retention, as suggested by the NIH guidelines [36]. For adolescents, Fat-Free Mass (FFM) was calculated using the prediction equation developed by our group [37], whereas for adults, the equation developed by Gray et al. [38] was used. FM $(\mathrm{kg})$ was derived as the difference between BM (kg) and FFM $(\mathrm{kg})$. As well, two blood pressure measurements (BP) were taken after participants had been sitting for at least 5 min, and the mean was used for statistical analysis.

\section{Lower Limb Muscle Power}

The Stairs Climbing Test (SCT) is a well-standardized procedure for measuring maximal anaerobic power in adolescents and adults with obesity $[30,39]$. Prior to administering the test, $2-3$ practise trials were scheduled to allow subjects to gain sufficient confidence with the technique. Briefly, subjects were asked to climb an ordinary stair at the highest possible speed, according to their abilities. The stairs consisted of 13 steps of $15.3 \mathrm{~cm}$ each, so that a total vertical distance of $1.99 \mathrm{~m}$ was covered. An experimenter measured the time taken to complete the test using a digital stopwatch. SCT repeatability in obese subjects has been previously evaluated in our laboratory and the coefficient of variation between measurements was found to be lower than $5 \%[30]$.

\section{Short Physical Performance Battery}

A Short Physical Performance Battery (SPPB) $[40,41]$ was administered. The SPPB consists of the following 3 parts: i. Tests of standing balance, included semi-tandem position, side-by-side stands and tandem position (each held for 10 seconds), ii. 
Walking a $4 \mathrm{~m}$ distance at normal gait speed, and iii. Rising from a chair and returning to the seated position 5 times. Scores for each item ranged from 0 to 4, for a maximum of 12 points. Performance categories were created for each set of performance measures to allow for analyses that included those unable to perform a task. The three tests of standing balance were considered hierarchical in difficulty by assigning a single score from 0 to 4 for standing balance [40] For $4 \mathrm{~m}$ walking and repeated chair stands, a score of 0 was assigned to those who could not complete the task. Those who were able to complete the task were assigned scores from 1 up to 4, corresponding to quartiles of time required for the task, with the fastest times scored as 4 [40]. Higher scores were associated with better lower limb functionality [41].

\section{Physical Performance Test}

The ability to perform ADL was assessed using the Physical Performance Test (PPT) [43]. The PPT test used in the present study includes 7 standardized tasks (i. Walk $15.2 \mathrm{~m}$, ii. Put on and take off a coat, iii. Pick up a coin, iv. Lift a book, v. Simulate the act of eating, vi. Perform a $360^{\circ}$ turn, and vii. Write a sentence). The score for each item ranged from 0 to 4 , with 0 corresponding to "unable to do" and 4 corresponding to "most able or quickest" [43]. The maximum score was 28 , and participants were classified as mildly to moderately frail if they scored between 19 and 24 [44].

\section{Statistical Analyses}

Statistical analyses were performed using Graph Pad Prism version 9.1.0-2021 software (GraphPad Software, Inc. - San Diego, CA, USA) with a significance set at $P<0.05$. All results were expressed as mean and standard deviation (SD). Normal distribution of the data was tested using the Kolmogorov-Smirnov test. The effects of gender, time, and the interaction between these variables on physical characteristics, body composition, lower limb muscle power, lower limb functionality and ability to perform ADL were tested using General Linear Model repeated measures. When significant differences were found, a Bonferroni post hoc test was evaluated implementing multiple comparisons. Relationships between the different factors were examined using Pearson or Spearman product-moment correlation coefficient.

\section{Results}

\section{Effects of the 3-week BWRP in adolescents}

\section{Anthropometric characteristics and body composition}

At T0, age, BM, BMI, and BMI-SDS were not significantly different between boys and girls, whereas stature was $~ 5 \%$ higher in boys than girls ( $p<0.001$, Tab. 1). At the end of BWRP (T21), BM (kg) and BMI decreased by $\varangle 4 \%(p<0.001, T a b .1)$ in both genders, a greater reduction ( 7\%, $p<0.001$, Tab. 1$)$ being observed in BMI-SDS in both genders.

At T0, FFM (kg) and FFM (\%) were 22 and 13\% higher in boys than in girls, respectively ( $p<0.001$, Tab. 1, Fig. 1A). Regarding FM (kg), no difference was found between boys and girls (Tab. 1, Fig. 1C), while FM expressed as a percentage was $~ 15 \%$ ( $<<$ 0.001, Tab. 1) lower in boys than in girls.

At T21, FFM (kg) decreased by 3\% ( $p=0.013$, Tab. 1) in boys only (Fig. 1C), while FFM (\%) increased by $\sim 3$ and $\sim 2 \%(p<0.005$, Tab. 1) in boys and girls, respectively. In contrast, FM (kg) decreased by $\sim 9$ and $\sim 7 \%$ in both boys and girls, respectively ( $p<$ 0.001 , Tab. 1, Fig. 1D), with a smaller decrease when FM was expressed as a percentage ( 3 and $\sim 2 \%$ in boys and girls, respectively, $p=0.017$, Tab. 1).

At T0, systolic BP $(\mathrm{mmHg})$ and diastolic BP $(\mathrm{mmHg})$ were not significantly different between boys and girls (Tab. 1). At T21, systolic BP and diastolic BP decreased by $\sim 7 \%$ in both genders $(p<0.001$, Tab. 1$)$.

\section{Physical capabilities}

At T0, SCT (s) and PPT scores were 11 and $~ 3 \%$ lower in boys than in girls, respectively $(p<0.05$, Tab. 1 ), while SPPB did not differ significantly between boys and girls (Tab. 1).

At T21, SCT (s) decreased by $\sim 5$ and $~ 7 \%(p<0.001)$ in boys and girls, respectively, while PPT score increased by $\sim 4 \%$ ( $p$ 
0.001, Tab. 1) in both boys and girls. The SPPB score did not change significantly in both genders (Tab. 1).

Changes in FM $(\triangle \mathrm{FM}, \mathrm{kg})$ were not related to changes in SCT $(\triangle \mathrm{SCT}, \mathrm{s})$, SPPB ( $\triangle \mathrm{SPPB}$, score), PPT ( $\triangle \mathrm{PPT}$, score), systolic BP $(\triangle \mathrm{SBP}, \mathrm{mmHg})$, and diastolic $\mathrm{BP}(\triangle \mathrm{DBP}, \mathrm{mmHg})$ in both boys and girls (Tab. 3$)$.

\section{Effects of the 3-week BWRP on adults}

\section{Anthropometric characteristics and body composition}

At T0, mean age and BMI did not differ significantly between males and females (Tab. 2), whereas stature and BM (kg) were significantly higher in males than females by $\sim 7$ and $\sim 10 \%$, respectively $(p<0.005$, Tab. 2$)$.

At T21 of BWRP, BM (kg) and BMI decreased by 5 and 4\% (p 0.001, Tab. 2) in males and females, respectively.

At T0, FFM (kg) and FFM (\%) were higher in males than females ( $+25 \%$ and $+17 \%$, respectively, $p<0.001)$, as shown in Tab. 2 and Fig. 2A. FM (kg) was not significantly different between males and females ( $p=0.240$, Tab. 2, Fig. 2C), with males having lower FM (\%) than females (-16\%, p 0.001, Tab. 2).

At T21, FFM (kg) decreased by 2\% in males and females with significant time interaction ( $\mathrm{p}=0.007)$ (Tab. 2, Fig. 2-B), while FFM (\%) increased in males $(\sim 4, \mathrm{p}<0.001)$ and females $(\sim 3 \%, \mathrm{p}=0.012)$ (Tab. 2). FM (kg) decreased by 10 and $\sim 6 \%$ in males and females, respectively ( $<<0.001$, Tab. 2, Fig. 2D), although a decrease was also observed when FM was expressed as a percentage, in both males ( 5\%, $p=0.002)$ and females $(\sim 2 \%, p=0.012)($ Tab. 2$)$.

At T0, systolic BP $(\mathrm{mmHg})$ at rest was greater in males $(+7 \%, \mathrm{p}=0.001$, Tab. 2$)$ than in females, while diastolic BP $(\mathrm{mmHg})$ did not differ significantly between the two genders. At T21, systolic BP $(\mathrm{mmHg})$ at rest reduced significantly in both males $(\sim 10 \%$, p 0.001$)$ and females $(\sim 5 \%, p=0.010$, Tab. 2$)$, while diastolic BP $(\mathrm{mmHg})$ reduced significantly by $\sim 6 \%$ in males only $(p=0.012$, Tab. 2).

\section{Physical capabilities}

At baseline, SCT (s) was lower in males than females by 5\% ( $p=0.042)$, whereas SPPB and PPT scores were not significantly different between the two genders (Tab. 2).

At T21, SCT (s) decreased significantly only in females by $\sim 16 \%$ ( $p<0.001$, Tab. 2). SPPB score increased by $\sim 7$ and $\sim 10 \%$ $(p<0.010$, Tab. 2) in males and females, respectively. Similarly, PPT score increased by mean $9 \%(p<0.001, T a b .2)$ in the two genders.

Changes in $F M(\triangle F M, k g)$ were inversely related to changes in both systolic $B P(\Delta S B P, m m H g)\left(R^{2}: 0.242, p=0.009, T a b .4\right)$ and diastolic $B P(\triangle D B P, m m H g)\left(R^{2}=0.203, p=0.009, T a b .4\right)$ in males. In obese females, changes in $F M(\Delta F M, k g)$ were inversely related to changes in both SPPB $\left(\triangle \mathrm{SPPB}\right.$, score) $\left(R^{2}: 0.345, \mathrm{p}<0.001\right.$, Tab. 4) and PPT ( $\triangle P P T$, score) $\left(R^{2}: 0.187, p=0.003, T a b\right.$. 4).

\section{Discussion}

The present study shows that a 3-week inpatient multidisciplinary BWRP, which includes physical training, moderate energy restriction, nutrition education, and psychological counselling, determines in adolescents and adults with obesity: 1) a significant reduction in BM and FM with a slight decrease in FFM, 2) improvements in SPPB and PPT scores and SCT time, and 3) a positive relationship between reduction in FM and reduction in systolic BP and diastolic BP in obese male adults. Our intervention was effective in reducing BM and FM for both adolescents and adults with obesity, in agreement with previous results reported in our laboratory after 3-week inpatient BWRP for patients aged 8-17 years[18, 44] and even for older obese male and females aged 61-75 year [45], confirming that body composition can be improved in obese individuals at any age. However, the positive effects exerted by our short-term BWRP on FM were associated with a slight reduction in FFM, probably because no specific strength training was considered in this first phase of metabolic rehabilitation of patients with obesity, as previously observed [46]. After a 3-week of BWRP, improvements in SPPB and PPT scores were observed in both adolescents and adults. SPPB is a test useful for assessing lower limb functionality (static balance, $4 \mathrm{~m}$ walking and lower limb strength) 
[47]. In our study, although SPPB scores were at the upper limit of normality (i.e., in the range of 11 to 12 points) [41], improvements of $\sim 0.8$ and $\sim 1$ points were found for male and female obese adults, respectively, after 3-week BWRP, whereas smaller improvements, albeit statistically significant, were found in obese adolescents. In this regard, our findings are relevant because multidisciplinary 3-week BWRP appears to positively affect lower limb functionality in tasks such as walking and in those requiring getting up and down from a chair, which are typically impaired in obese patients [48-50], and could improve their quality of life. PPT is useful in assessing functional capabilities as it mimics ADL [43, 52-53]. Previous studies showed that obese subjects had perceived difficulty performing physical exercise and ADL[14-17] In the present study, the PPT score increased in both obese adolescents and adults, suggesting that a structured exercise program in a 3-week BWRP can improve the ability to perform ADL. Our findings are consistent with those recently reported by Wilson et al.[54], showing that regular physical activity and moderate energy restriction have positive effects on physical performance and thus quality of life. Similarly, BWRP induced FM loss, which emerges as the major significant predictor of improvements in SPPB and PPT scores in adult obese females. At T0, mean SPPB and PPT scores in our obese females were lower than 11 and 28, respectively, and these two scores are considered signs of poor lower limb functionality $[55,56]$. Several factors have been considered to explain lower limb physical performance in females compared to males, such as lower muscle strength [57], higher body fat [57], lower muscle mass [58], and greater muscle fat infiltration[59] with the greatest adipose tissue thickness in the lower limbs [60]. In addition, a modified Margaria test[61] has been used previously to assess lower limb muscle power in obese subjects[20] and it has been used clinically to assess motor performance in response to BWRP $[18,20,21,30,62,63]$. In the present study, SCT time reduced at T21, although there was no direct correlation between the BM reduction and the improvement in SCT time, as previously observed by our research group [28]. It seems plausible to hypothesize that the reduction of BM may be associated with reduced body inertia[64] and the reduction of intramyocellular lipids may have played a role in the improvement of SCT time [65].

In addition, reduction of FM was positively related to a reduction in systolic BP and diastolic BP only in obese males. Visceral adiposity is generally higher in obese male adults than in female counterparts [66], and visceral fat has been linked to the secretion of adipocytokines, that contribute to the development and progression of hypertension [66, 67]. BWRP should reduce the low-grade chronic inflammatory state, known to characterize visceral adiposity, with an improvement in cardiometabolic profile $[68,69]$.

\section{Conclusions}

In conclusion, our study confirms that a 3-week inpatient multidisciplinary BWRP, even if it only detects a 4-5\% reduction in BM, is able to induce a significant reduction in FM, improvements in lower limb functionality and lower limb muscle power, and improvements in performing $A D L$, all of which are positive changes highly relevant to the progressive multidisciplinary rehabilitation of adolescents and adults with obesity.

\section{Abbreviations}

ADL: activities of daily living, BM: body mass, BMl: body mass index, BMI (SDS): body mass index standard deviation score, BP: blood pressure, BWRP: body weight-reduction programs, DBP: diastolic blood pressure, HR: heart rate, PPT. physical performance test, SBP: systolic blood pressure, SCT, stair climbing test, SPPB, short physical performance battery,

\section{Declarations}

\section{Ethics approval and consent to participate}

The studies were reviewed and approved by the Ethical Committee of Istituto Auxologico Italiano (Milan, Italy). Written informed consent to participate in this study was provided by the participants' legal representatives if the participants were under 18 years of age.

\section{Consent for publication}


Not applicable.

\section{Availability of data and materials}

All data generated or analysed during this study are included in this published article.

\section{Conflict of Interest}

The authors declare that the research was conducted in the absence of any commercial or financial relationships that could be construed as a potenial conflict of interest.

\section{Funding}

The study was supported by Progetti di Ricerca Corrente (research code: 01C124, acronym: PRORIPONATFIS), Istituto Auxologico Italiano, IRCCS, Milan, Italy and by Fondazione Pietro Pittini, Trieste, Italy.

\section{Author Contributions}

Conceptualization, A.S., S.L., M.D.A., F.V., Data curation, A.S., M.D.A., S.L., F.V., G.T., R.D.M, Formal analysis, F.V., M.D.A., Funding acquisition, A.S., Investigation, G.T., R.D.M. Project administration, A.S., Supervision, A.S., Writing original draft, M.D.A., Writing, review \& editing, A.S., M.D.A., S.L., F.V. All authors have read and agreed to the published version of the manuscript.

\section{Acknowledgments}

We are grateful to adolescents (and their parents) and adults for participating in the present study, to the nursing staff at the Division of Auxology and at the Division of Metabolic Diseases, Istituto Auxologico Italiano, IRCCS, Piancavallo (VB) for their qualified assistance during the execution of the functional tests.

\section{References}

1. Cancela Carral J, Ayán C, Sturzinger L, Gonzalez G. Relationship Between Body Mass Index and Static and Dynamic Balance in Active and Inactive Older Adults. Journal of Geriatric Physical Therapy. 2018,42:1.

2. Inoue Y, Qin B, Poti J, Sokol R, Gordon-Larsen P. Epidemiology of Obesity in Adults: Latest Trends. Current obesity reports. 2018,7:276-88.

3. Guthold R, Stevens GA, Riley LM, Bull FC. Worldwide trends in insufficient physical activity from 2001 to 2016: a pooled analysis of 358 population-based surveys with 1.9 million participants. The Lancet Global Health. Elsevier BV, 2018,6:e1077-86.

4. Lim SS, Vos T, Flaxman AD, Danaei G, Shibuya K, Adair-Rohani H, et al. A comparative risk assessment of burden of disease and injury attributable to 67 risk factors and risk factor clusters in 21 regions, 1990-2010: a systematic analysis for the Global Burden of Disease Study 2010. The Lancet. Elsevier BV, 2012,380:2224-60.

5. Swinburn B. Commentary: Physical activity as a minor player in the obesity epidemic: what are the deep implications? International Journal of Epidemiology. 2013,42:1838-40.

6. Brady TM. Obesity-Related Hypertension in Children. Frontiers in pediatrics. Frontiers Media S.A., 2017,5:197.

7. Henry SL, Barzel B, Wood-Bradley RJ, Burke SL, Head GA, Armitage JA. Developmental origins of obesity-related hypertension. Clinical and experimental pharmacology \& physiology. Australia, 2012,39:799-806.

8. Kannel WB, Higgins M. Smoking and hypertension as predictors of cardiovascular risk in population studies. Journal of hypertension Supplement: official journal of the International Society of Hypertension. England, 1990,8:S3-8.

9. Faulkner JL, Belin de Chantemèle EJ. Sex Differences in Mechanisms of Hypertension Associated With Obesity. Hypertension (Dallas, Tex: 1979). 2017/11/13. 2018,71:15-21. 
10. T. CA, C. HK, Constadina P, G.S. SG, M. DA. Childhood Obesity and Cardiovascular Dysfunction. Journal of the American College of Cardiology. American College of Cardiology Foundation, 2013,62:1309-19.

11. Loftin M, Sothern M, Trosclair L, O'Hanlon A, Miller J, Udall J. Scaling VO(2) peak in obese and non-obese girls. Obesity research. United States, 2001,9:290-6.

12. Thivel D, Isacco L, Lazaar N, Aucouturier J, Ratel S, Doré E, et al. Effect of a 6-month school-based physical activity program on body composition and physical fitness in lean and obese schoolchildren. European journal of pediatrics. Germany, 2011,170:1435-43.

13. Török K, Szelényi Z, Pórszász J, Molnár D. Low physical performance in obese adolescent boys with metabolic syndrome. International journal of obesity and related metabolic disorders: journal of the International Association for the Study of Obesity. England, 2001,25:966-70.

14. Backholer K, Wong E, Freak-Poli R, Walls HL, Peeters A. Increasing body weight and risk of limitations in activities of daily living: a systematic review and meta-analysis. Obesity reviews: an official journal of the International Association for the Study of Obesity. England, 2012,13:456-68.

15. Tareque Mdl, Saito Y, Chan A, Visaria A, Ma S, Malhotra R. Years of life with and without limitation in physical function and in activities of daily living by body mass index among older adults. International Journal of Obesity. 2019,43:224453.

16. Vásquez E, Batsis JA, Germain CM, Shaw BA. Impact of obesity and physical activity on functional outcomes in the elderly: data from NHANES 2005-2010. Journal of aging and health. 2014/06/09. 2014,26:1032-46.

17. Valerio G, Licenziati MR, Manco M, Ambruzzi AM, Bacchini D, Baraldi E, et al. [Health consequences of obesity in children and adolescents]. Minerva pediatrica. Italy, 2014,66:381-414.

18. Maffiuletti NA, De Col A, Agosti F, Ottolini S, Moro D, Genchi M, et al. Effect of a 3-week body mass reduction program on body composition, muscle function and motor performance in pubertal obese boys and girls. Journal of Endocrinological Investigation. 2004,27:813-20.

19. Sartorio A, Agosti F, De Col A, Lafortuna CL. Age- and gender-related variations of leg power output and body composition in severely obese children and adolescents. Journal of endocrinological investigation. Italy, 2006,29:48-54.

20. Lafortuna CL, Fumagalli E, Vangeli V, Sartorio A. Lower limb alactic anaerobic power output assessed with different techniques in morbid obesity. Journal of endocrinological investigation. Italy, 2002,25:134-41.

21. Lafortuna CL, Agosti F, Marinone PG, Marazzi N, Sartorio A. The relationship between body composition and muscle power output in men and women with obesity. Journal of endocrinological investigation. Italy, 2004,27:854-61.

22. Lafortuna CL, Maffiuletti NA, Agosti F, Sartorio A. Gender variations of body composition, muscle strength and power output in morbid obesity. International journal of obesity (2005). England, 2005,29:833-41.

23. Sartorio A, Lafortuna CL, Silvestri G, Narici M V. Effects of short-term, integrated body mass reduction program on maximal oxygen consumption and anaerobic alactic performance in obese subjects. Diabetes, nutrition \& metabolism. Italy, 2003,16:24-31.

24. Deforche BI, Hills AP, Worringham CJ, Davies PSW, Murphy AJ, Bouckaert JJ, et al. Balance and postural skills in normalweight and overweight prepubertal boys. International journal of pediatric obesity: IJPO: an official journal of the International Association for the Study of Obesity. England, 2009,4:175-82.

25. do Nascimento JA, Silva CC, Dos Santos HH, de Almeida Ferreira JJ, de Andrade PR. A preliminary study of static and dynamic balance in sedentary obese young adults: the relationship between BMI, posture and postural balance. Clinical obesity. England, 2017,7:377-83.

26. Cimolin V, Cau N, Galli M, Capodaglio P. Balance control in obese subjects during quiet stance: A state-of-the art. Applied Sciences (Switzerland). 2020,10.

27. Forhan M, Gill S V. Obesity, functional mobility and quality of life. Best Practice and Research: Clinical Endocrinology and Metabolism. Elsevier Ltd, 2013,27:129-37. 
28. Rigamonti AE, Cicolini S, Caroli D, De Col A, Scacchi M, Cella SG, et al. Effects of a 3-week in-hospital body weight reduction program on cardiovascular risk factors, muscle performance, and fatigue: A retrospective study in a population of obese adults with or without metabolic syndrome. Nutrients. 2020,12.

29. Scott D, Shore-Lorenti C, McMillan LB, Mesinovic J, Clark RA, Hayes A, et al. Calf muscle density is independently associated with physical function in overweight and obese older adults. Journal of musculoskeletal \& neuronal interactions. 2018,18:9-17.

30. Sartorio A, Narici M V, Fumagalli E, Faglia G, Lafortuna CL. Aerobic and anaerobic performance before and after a shortterm body mass reduction program in obese subjects. Diabetes, nutrition \& metabolism. Italy, 2001,14:51-7.

31. Roberts CK, Lee MM, Katiraie M, Krell SL, Angadi SS, Chronley MK, et al. Strength fitness and body weight status on markers of cardiometabolic health. Medicine and science in sports and exercise. 2015,47:1211-8.

32. Cole TJ, Freeman J V, Preece MA. British 1990 growth reference centiles for weight, height, body mass index and head circumference fitted by maximum penalized likelihood. Statistics in medicine. England, 1998,17:407-29.

33. Nutrition ISo (1996) Recommended levels of energy and nutri-ents intake for the Italian population (LARN). Edra Medical Publishing and New Media M. No Title.

34. Cacciari E, Milani S, Balsamo A, Dammacco F, De Luca F, Chiarelli F, et al. Italian cross-sectional growth charts for height, weight and BMI (6-20 y). European journal of clinical nutrition. England, 2002,56:171-80.

35. Lukaski HC. Methods for the assessment of human body composition: traditional and new. The American journal of clinical nutrition. United States, 1987,46:537-56.

36. Bioelectrical impedance analysis in body composition measurement: National Institutes of Health Technology Assessment Conference Statement. The American journal of clinical nutrition. United States, 1996,64:524S-532S.

37. Lazzer S, Bedogni G, Agosti F, De Col A, Mornati D, Sartorio A. Comparison of dual-energy X-ray absorptiometry, air displacement plethysmography and bioelectrical impedance analysis for the assessment of body composition in severely obese Caucasian children and adolescents. The British journal of nutrition. England, 2008,100:918-24.

38. Gray DS, Bray GA, Gemayel N, Kaplan K. Effect of obesity on bioelectrical impedance. The American journal of clinical nutrition. United States, 1989,50:255-60.

39. Sartorio A, Proietti M, Marinone P, Agosti F, Adorni F, Lafortuna C. Influence of gender, age and BMI on lower limb muscular power output in a large population of obese men and women. International journal of obesity and related metabolic disorders: journal of the International Association for the Study of Obesity. 2004,28:91-8.

40. Guralnik JM, Simonsick EM, Ferrucci L, Glynn RJ, Berkman LF, Blazer DG, et al. A short physical performance battery assessing lower extremity function: Association with self-reported disability and prediction of mortality and nursing home admission. Journals of Gerontology. 1994,49.

41. Ostir G V, Volpato S, Fried LP, Chaves P, Guralnik JM. Reliability and sensitivity to change assessed for a summary measure of lower body function: results from the Women's Health and Aging Study. Journal of clinical epidemiology. United States, 2002,55:916-21.

42. Guralnik JM, Simonsick EM, Ferrucci L, Glynn RJ, Berkman LF, Blazer DG, et al. A short physical performance battery assessing lower extremity function: Association with self-reported disability and prediction of mortality and nursing home admission. Journals of Gerontology. 1994,49.

43. Reuben DB, Siu AL. An objective measure of physical function of elderly outpatients. The Physical Performance Test. Journal of the American Geriatrics Society. United States, 1990,38:1105-12.

44. Brown M, Sinacore DR, Binder EF, Kohrt WM. Physical and performance measures for the identification of mild to moderate frailty. The journals of gerontology Series A, Biological sciences and medical sciences. United States, 2000,55:M350-5.

45. Lazzer S, Lafortuna C, Busti C, Galli R, Agosti F, Sartorio A. Effects of low- and high-intensity exercise training on body composition and substrate metabolism in obese adolescents. Journal of Endocrinological Investigation. 2011,34:45-52. 
46. Sartorio A, Lafortuna CL, Agosti F, Proietti M, Maffiuletti NA. Elderly obese women display the greatest improvement in stair climbing performance after a 3-week body mass reduction program. International journal of obesity and related metabolic disorders: journal of the International Association for the Study of Obesity. England, 2004,28:1097-104.

47. Stiegler P, Cunliffe A. The Role of Diet and Exercise for the Maintenance of Fat-Free Mass and Resting Metabolic Rate During Weight Loss. Sports Medicine. 2006,36:239-62.

48. Perera S, Mody SH, Woodman RC, Studenski SA. Meaningful change and responsiveness in common physical performance measures in older adults. Journal of the American Geriatrics Society. United States, 2006,54:743-9.

49. Dufek JS, Currie RL, Gouws P-L, Candela L, Gutierrez AP, Mercer JA, et al. Effects of overweight and obesity on walking characteristics in adolescents. Human movement science. Netherlands, 2012,31:897-906.

50. Galli M, Crivellini M, Sibella F, Montesano A, Bertocco P, Parisio C. Sit-to-stand movement analysis in obese subjects. International Journal of Obesity. 2000,24:1488-92.

51. Kim S-H, Ju S-K. Comparison of muscle activity during sit-to-stand movement at different chair heights between obese and normal-weight subjects. Journal of exercise rehabilitation. Korean Society of Exercise Rehabilitation, 2021,17:39-44.

52. Bittel DC, Bittel AJ, Tuttle LJ, Hastings MK, Commean PK, Mueller MJ, et al. Adipose tissue content, muscle performance and physical function in obese adults with type 2 diabetes mellitus and peripheral neuropathy. Journal of diabetes and its complications. 2015,29:250-7.

53. Stoever K, Heber A, Eichberg S, Brixius K. Influences of Resistance Training on Physical Function in Older, Obese Men and Women with Sarcopenia. Journal of Geriatric Physical Therapy. 2018,41:20-7.

54. Villareal DT, Chode S, Parimi N, Sinacore DR, Hilton T, Armamento-Villareal R, et al. Weight loss, exercise, or both and physical function in obese older adults. Obstetrical and Gynecological Survey. 2011,66:488-9.

55. Wilson K. Obesity: Lifestyle Modification and Behavior Interventions. FP essentials. United States, 2020,492:19-24.

56. Bergland A, Strand BH. Norwegian reference values for the Short Physical Performance Battery (SPPB): The Troms $\varnothing$ Study. BMC Geriatrics. BMC Geriatrics, 2019,19:1-10.

57. Gregorio L, Brindisi J, Kleppinger A, Sullivan R, Mangano KM, Bihuniak JD, et al. Adequate dietary protein is associated with better physical performance among post-menopausal women 60-90 years. The journal of nutrition, health \& aging. 2014,18:155-60.

58. Tseng LA, Delmonico MJ, Visser M, Boudreau RM, Goodpaster BH, Schwartz A V, et al. Body Composition Explains Sex Differential in Physical Performance Among Older Adults. The Journals of Gerontology: Series A. 2014,69:93-100.

59. Sternfeld B, Ngo L, Satariano WA, Tager IB. Associations of Body Composition with Physical Performance and Selfreported Functional Limitation in Elderly Men and Women. American Journal of Epidemiology. 2002,156:110-21.

60. Goodpaster BH, Carlson CL, Visser M, Kelley DE, Scherzinger A, Harris TB, et al. Attenuation of skeletal muscle and strength in the elderly: The Health ABC Study. Journal of Applied Physiology. American Physiological Society, 2001,90:2157-65.

61. Krotkiewski M, Bjorntorp P, Sjostrom L, Smith U. Impact of obesity on metabolism in men and women. Importance of regional adipose tissue distribution. Journal of Clinical Investigation. 1983,72:1150-62.

62. Margaria R, Aghemo P, Rovelli E. Measurement of muscular power (anaerobic) in man. Journal of Applied Physiology. American Physiological Society, 1966,21:1662-4.

63. Sartorio A, Fontana P, Trecate L, Lafortuna CL. Short-term changes of fatigability and muscle performance in severe obese patients after an integrated body mass reduction program. Diabetes, nutrition \& metabolism. Italy, 2003,16:88-93.

64. Sartorio A, Maffiuletti NA, Agosti F, Lafortuna CL. Gender-related changes in body composition, muscle strength and power output after a short-term multidisciplinary weight loss intervention in morbid obesity. Journal of endocrinological investigation. Italy, 2005,28:494-501.

65. Thivel D, Ring-Dimitriou S, Weghuber D, Frelut ML, O'Malley G. Muscle strength and fitness in pediatric obesity: A systematic review from the european childhood obesity group. Obesity Facts. 2016,9:52-63. 
66. Choi SJ, Files DC, Zhang T, Wang ZM, Messi ML, Gregory H, et al. Intramyocellular lipid and impaired myofiber contraction in normal weight and obese older adults. Journals of Gerontology - Series A Biological Sciences and Medical Sciences. 2016,71:557-64.

67. Thomas EL, Saeed N, Hajnal J V, Brynes A, Goldstone AP, Frost G, et al. Magnetic resonance imaging of total body fat. Journal of applied physiology (Bethesda, Md: 1985). United States, 1998,85:1778-85.

68. Carobbio S, Rodriguez-Cuenca S, Vidal-Puig A. Origins of metabolic complications in obesity: ectopic fat accumulation. The importance of the qualitative aspect of lipotoxicity. Current opinion in clinical nutrition and metabolic care. England, 2011,14:520-6.

69. Karastergiou K, Fried SK. Multiple adipose depots increase cardiovascular risk via local and systemic effects. Current atherosclerosis reports. 2013,15:361.

70. Bianchi VE. Weight loss is a critical factor to reduce inflammation. Clinical Nutrition ESPEN. Elsevier, 2018,28:21-35.

71. Bianchi VE. Weight loss is a critical factor to reduce inflammation. Clinical Nutrition ESPEN [Internet]. Elsevier, 2018,28:21-35. Available from: https://doi.org/10.1016/j.clnesp.2018.08.007

\section{Tables}

Table 1. Physical characteristics of adolescents with obesity before (T0) and after (T21) the 3-week BWRP. 


\begin{tabular}{|c|c|c|c|c|c|c|c|c|c|c|c|c|c|c|c|}
\hline & \multicolumn{6}{|c|}{ Boys (n: 56) } & \multicolumn{6}{|c|}{ Girls (n: 83) } & \multicolumn{3}{|l|}{$P$} \\
\hline & T0 & & & T21 & & & TO & & & T21 & & & G & $\mathrm{T}$ & $G \times T$ \\
\hline Age (y) & 14.9 & \pm & 2.0 & & & & 15.0 & \pm & 2.1 & & & & 0.841 & & \\
\hline $\begin{array}{l}\text { Stature } \\
(\mathrm{m})\end{array}$ & 1.68 & \pm & 0.11 & & & & 1.60 & \pm & 0.07 & & & & 0.001 & & \\
\hline $\begin{array}{l}\text { Body } \\
\text { mass } \\
(\mathrm{kg})\end{array}$ & 103.3 & \pm & 22.7 & 98.7 & \pm & 21.8 & 96.8 & \pm & 21.3 & 92.7 & \pm & 20.2 & 0.095 & 0.001 & 0.154 \\
\hline $\begin{array}{l}\mathrm{BMI} \\
\left(\mathrm{kg} / \mathrm{m}^{2}\right)\end{array}$ & 36.4 & \pm & 5.7 & 34.8 & \pm & 5.6 & 37.5 & \pm & 7.3 & 35.9 & \pm & 6.9 & 0.338 & 0.001 & 0.906 \\
\hline $\begin{array}{l}\text { BMI } \\
\text { (SDS) }\end{array}$ & 2.9 & \pm & 0.6 & 2.7 & \pm & 0.6 & 2.9 & \pm & 0.6 & 2.4 & \pm & 0.6 & 0.637 & 0.001 & 0.028 \\
\hline $\begin{array}{l}\text { Fat-free } \\
\text { mass } \\
(\mathrm{kg})\end{array}$ & 59.3 & \pm & 11.6 & 57.4 & \pm & 13.3 & 48.6 & \pm & 7.6 & 47.7 & \pm & 7.8 & 0.001 & 0.003 & 0.226 \\
\hline $\begin{array}{l}\text { Fat-free } \\
\text { mass (\%) }\end{array}$ & 57.8 & \pm & 5.5 & 59.5 & \pm & 6.7 & 51.1 & \pm & 6.6 & 52.5 & \pm & 7.2 & 0.001 & 0.001 & 0.635 \\
\hline $\begin{array}{l}\text { Fat Mass } \\
\mathrm{kg})\end{array}$ & 44.0 & \pm & 13.4 & 40.1 & \pm & 14.5 & 48.0 & \pm & 16.1 & 44.8 & \pm & 15.3 & 0.091 & 0.001 & 0.345 \\
\hline $\begin{array}{l}\text { Fat Mass } \\
(\%)\end{array}$ & 42.2 & \pm & 7.7 & 40.5 & \pm & 6.7 & 48.4 & \pm & 6.7 & 47.4 & \pm & 7.3 & 0.001 & 0.002 & 0.503 \\
\hline $\begin{array}{l}\text { SBP } \\
(\mathrm{mmHg})\end{array}$ & 126.0 & \pm & 11.0 & 117.6 & \pm & 10.2 & 124.8 & \pm & 10.6 & 116.0 & \pm & 7.8 & 0.335 & 0.001 & 0.834 \\
\hline $\begin{array}{l}\text { DBP } \\
(\mathrm{mmHg})\end{array}$ & 77.9 & \pm & 7.2 & 74.2 & \pm & 6.4 & 76.5 & \pm & 7.0 & 72.6 & \pm & 5.7 & 0.128 & 0.001 & 0.875 \\
\hline SCT (s) & 2.9 & \pm & 0.4 & 2.7 & \pm & 0.4 & 3.5 & \pm & 0.5 & 3.0 & \pm & 0.4 & 0.001 & 0.001 & 0.112 \\
\hline $\begin{array}{l}\text { SPPB } \\
\text { score }\end{array}$ & 11.9 & \pm & 0.4 & 12.0 & \pm & 0.1 & 11.9 & \pm & 0.2 & 12.0 & \pm & 0 & 0.124 & 0.027 & 0.465 \\
\hline $\begin{array}{l}\text { PPT } \\
\text { score }\end{array}$ & 25.5 & \pm & 1.6 & 26.6 & \pm & 1.2 & 26.1 & \pm & 1.3 & 27.1 & \pm & 1.0 & 0.012 & 0.001 & 0.319 \\
\hline
\end{tabular}

All values are mean and standard deviation (SD). BMI, body mass index, BMI (SDS), body mass index standard deviation score, SBP, systolic blood pressure, DBP, diastolic blood pressure, HR, heart rate, SCT, stair climbing test, SPPB, short physical performance battery, PPT, physical performance test. Gender $(G)$ and Time $(T)$, Gender $\times$ time interaction $(G \times T)$.

Table 2. Physical characteristics of adults with obesity before (T0) and after (T21) the 3-week BWRP. 


\begin{tabular}{|c|c|c|c|c|c|c|c|c|c|c|c|c|c|c|c|}
\hline & \multicolumn{6}{|c|}{ Males (n: 27) } & \multicolumn{6}{|c|}{ Females (n: 44) } & \multicolumn{3}{|l|}{$P$} \\
\hline & TO & & & $\mathrm{T} 21$ & & & TO & & & $\mathrm{T} 21$ & & & G & $\mathrm{T}$ & $G \times T$ \\
\hline Age (y) & 56.8 & \pm & 11.2 & & & & 50.9 & \pm & 15.1 & & & & 0.060 & & \\
\hline $\begin{array}{l}\text { Stature } \\
\text { (m) }\end{array}$ & 1.71 & \pm & 0.06 & & & & 1.60 & \pm & 0.06 & & & & 0.001 & & \\
\hline $\begin{array}{l}\text { Body } \\
\text { mass } \\
(\mathrm{kg})\end{array}$ & 125.8 & \pm & 16.0 & 119.0 & \pm & 14.9 & 113.9 & \pm & 16.5 & 109.2 & \pm & 15.7 & 0.007 & 0.001 & 0.001 \\
\hline $\begin{array}{l}\mathrm{BMI} \\
\left(\mathrm{kg} / \mathrm{m}^{2}\right)\end{array}$ & 43.1 & \pm & 3.6 & 40.8 & \pm & 3.3 & 44.9 & \pm & 5.8 & 43.0 & \pm & 6.0 & 0.101 & 0.001 & 0.001 \\
\hline $\begin{array}{l}\text { Fat-free } \\
\text { mass } \\
(\mathrm{kg})\end{array}$ & 66.5 & \pm & 7.4 & 65.3 & \pm & 6.6 & 49.6 & \pm & 4.1 & 48.8 & \pm & 3.5 & 0.001 & 0.007 & 0.650 \\
\hline $\begin{array}{l}\text { Fat-free } \\
\text { mass } \\
(\%)\end{array}$ & 53.1 & \pm & 4.3 & 55.2 & \pm & 4.3 & 44.1 & \pm & 5.1 & 45.2 & \pm & 4.8 & 0.001 & 0.001 & 0.128 \\
\hline $\begin{array}{l}\text { Fat } \\
\text { mass } \\
(\mathrm{kg})\end{array}$ & 59.3 & \pm & 11.3 & 53.6 & \pm & 10.8 & 64.3 & \pm & 14.6 & 60.4 & \pm & 13.6 & 0.067 & 0.001 & 0.046 \\
\hline $\begin{array}{l}\text { Fat } \\
\text { Mass } \\
(\%)\end{array}$ & 46.9 & \pm & 4.3 & 44.8 & \pm & 4.3 & 55.9 & \pm & 5.1 & 54.7 & \pm & 4.8 & 0.001 & 0.001 & 0.129 \\
\hline $\begin{array}{l}\text { SBP } \\
(\mathrm{mmHg})\end{array}$ & 143.1 & \pm & 12.3 & 129.3 & \pm & 11.7 & 133.5 & \pm & 12.7 & 127.6 & \pm & 10.0 & 0.015 & 0.001 & 0.018 \\
\hline $\begin{array}{l}\text { DBP } \\
(\mathrm{mmHg})\end{array}$ & 85.2 & \pm & 8.6 & 80.0 & \pm & 6.2 & 82.2 & \pm & 8.8 & 80.1 & \pm & 5.1 & 0.285 & 0.003 & 0.183 \\
\hline SCT (s) & 4.3 & \pm & 1.2 & 3.8 & \pm & 0.9 & 6.5 & \pm & 5.3 & 5.6 & \pm & 3.9 & 0.035 & 0.001 & 0.230 \\
\hline $\begin{array}{l}\text { SPPB } \\
\text { (score) }\end{array}$ & 11.1 & \pm & 1.3 & 11.8 & \pm & 0.5 & 10.2 & \pm & 2.5 & 11.2 & \pm & 1.6 & 0.085 & $<0.001$ & 0.473 \\
\hline $\begin{array}{l}\text { PPT } \\
\text { (score) }\end{array}$ & 24.4 & \pm & 2.4 & 26.7 & \pm & 1.2 & 24.2 & \pm & 4.4 & 26.4 & \pm & 3.4 & 0.787 & $<0,001$ & 0.834 \\
\hline
\end{tabular}

All values are mean and standard deviation (SD). BMI, body mass index, SBP, systolic blood pressure, DBP, diastolic blood pressure,

HR, heart rate, SCT, stair climbing test, SPPB, short physical performance battery, PPT, physical performance test. Gender $(G)$ and Time $(T)$, Gender $\times$ time interaction $(G \times T)$.

Table 3. Linear regression between changes in Fat Mass $(\Delta \mathrm{FM})$ in adolescents with obesity and possible predictors. 


\begin{tabular}{lllll} 
& \multicolumn{2}{l}{ Boys (n: 56) } & \multicolumn{2}{l}{ Girls (n: 83) } \\
\hline & $\mathrm{R}^{2}$ & $\mathrm{p}$-value & $\mathrm{R}^{2}$ & $\mathrm{p}$-value \\
\hline$\Delta$ SCT (s) & 0.007 & 0.523 & 0.008 & 0.416 \\
\hline & & & & \\
\hline$\Delta$ SPPB (score) & 0.057 & 0.076 & 0.032 & 0.103 \\
\hline & & & & \\
\hline$\Delta$ PPT (score) & 0.002 & 0.719 & 0.015 & 0.271 \\
\hline & & & & \\
\hline$\Delta$ SBP (mmHg) & 0.046 & 0.110 & 0.008 & 0.415 \\
\hline & & & & \\
\hline$\Delta$ DBP (mmHg) & 0.013 & 0.523 & 0.043 & 0.059
\end{tabular}

SCT, stair climbing test, SPPB, short physical performance battery, PPT, physical performance test, SBP, systolic blood pressure, DBP, diastolic blood pressure, $\Delta$ is the difference of the values between the completing and the beginning of the weight reduction program.

Table 4. Linear regression between changes in Fat Mass $(\Delta \mathrm{FM})$ in adults with obesity and possible predictors.

\begin{tabular}{lllll} 
& \multicolumn{2}{l}{ Males (n: 27) } & \multicolumn{2}{l}{ Females (n: 44) } \\
\hline & $\mathrm{R}^{2}$ & $\mathrm{p}$-value & $\mathrm{R}^{2}$ & $\mathrm{p}$-value \\
\hline$\Delta$ SCT (s) & 0.002 & 0.942 & 0.030 & 0.278 \\
\hline & & & & \\
\hline$\Delta$ SPPB (score) & 0.002 & 0.837 & 0.346 & 0.001 \\
\hline & & & & \\
\hline$\Delta$ PPT (score) & 0.002 & 0.816 & 0.187 & 0.003 \\
\hline & & & & \\
\hline$\Delta$ SBP (mmHg) & 0.242 & 0.009 & 0.001 & 0.802 \\
\hline & & & & \\
\hline$\Delta$ DBP (mmHg) & 0.203 & 0.018 & 0.025 & 0.297
\end{tabular}

SCT, stair climbing test, SPPB, short physical performance battery, PPT, physical performance test, SBP, systolic blood pressure, DBP, diastolic blood pressure, $\triangle$ is the difference of the values between the completing and the beginning of the weight reduction program.

\section{Figures}




\section{T0}

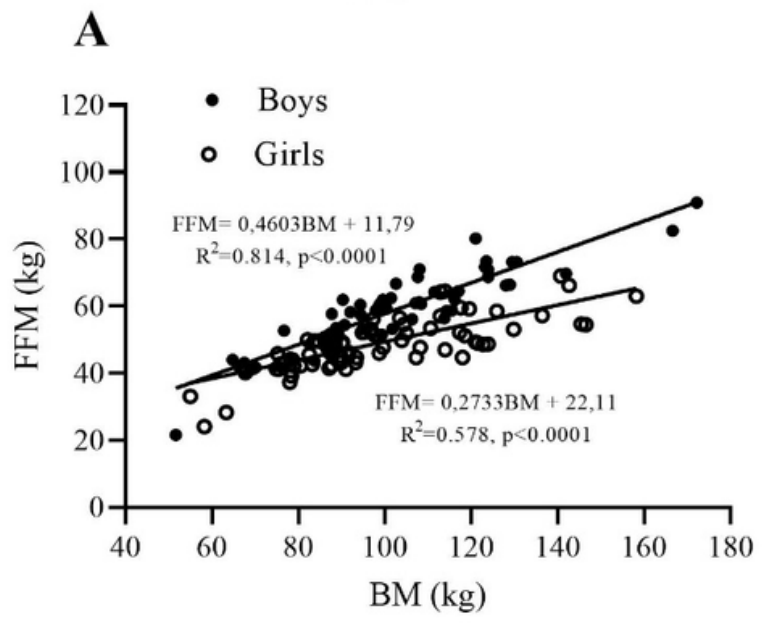

C

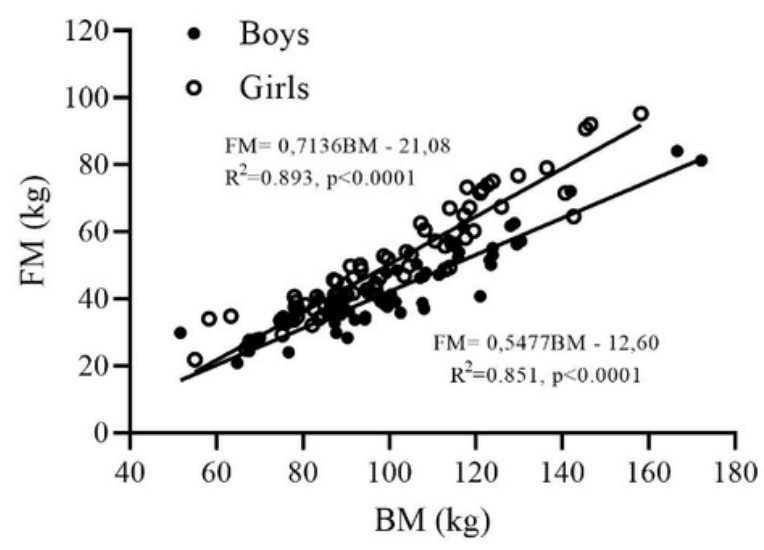

T21

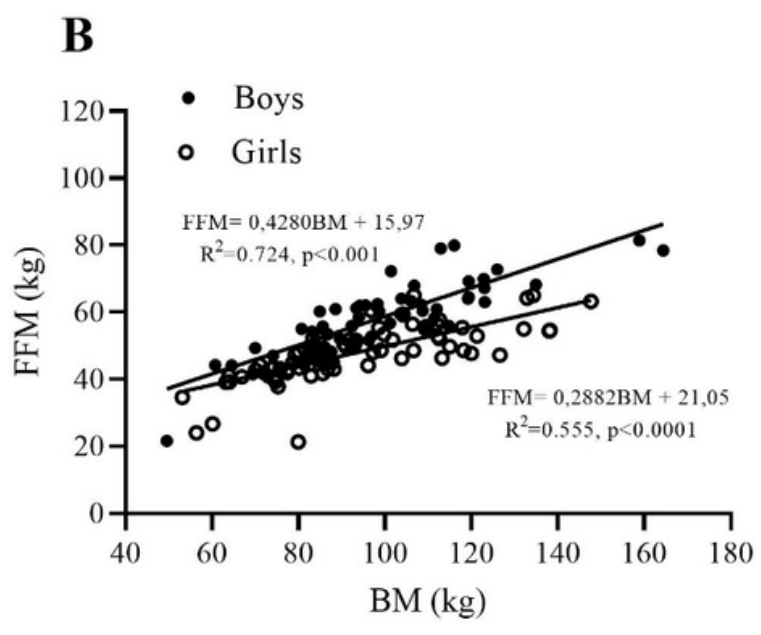

D

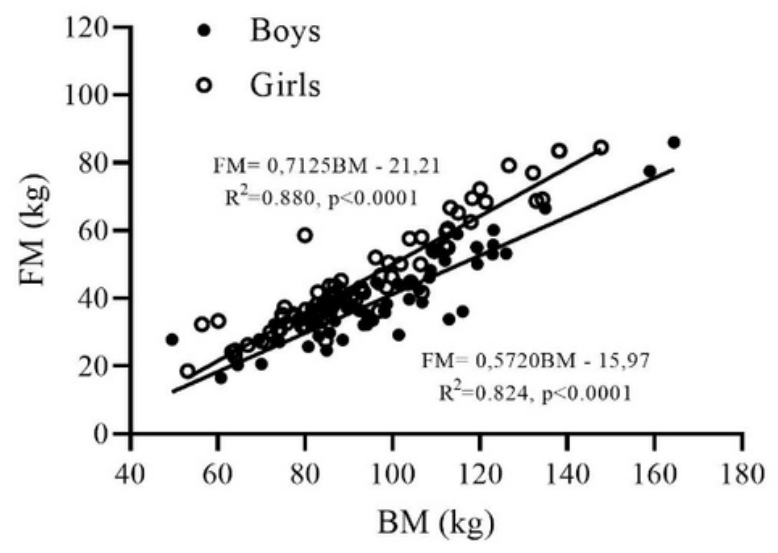

\section{Figure 1}

Fat-free mass (FFM, panel A and B) and fat mass (FM, panel $C$ and D) are plotted as a function of body mass in adolescent obese boys (closed symbols) and girls (open symbols) before (T0) and after (T21) the 3-week BWRP. 
T0

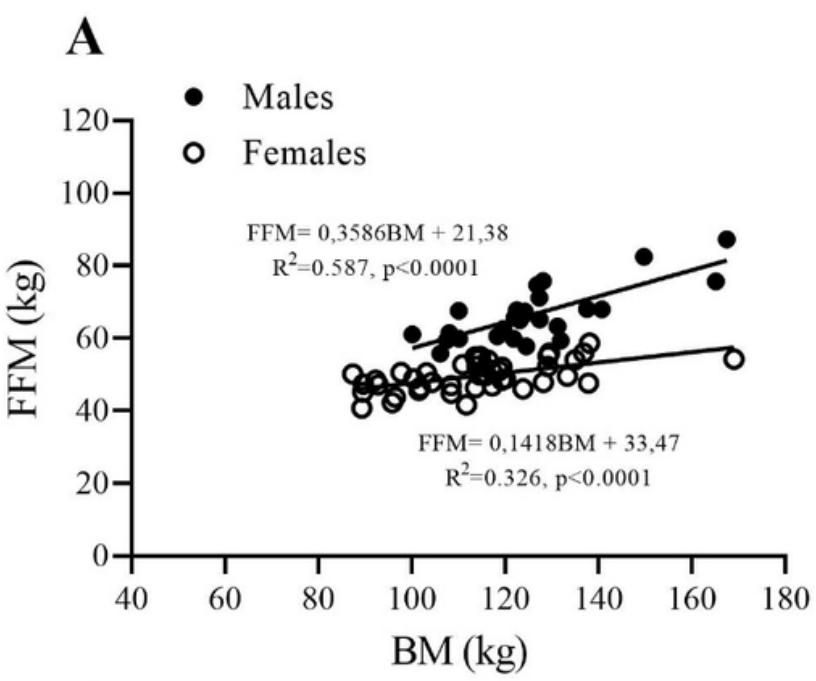

C

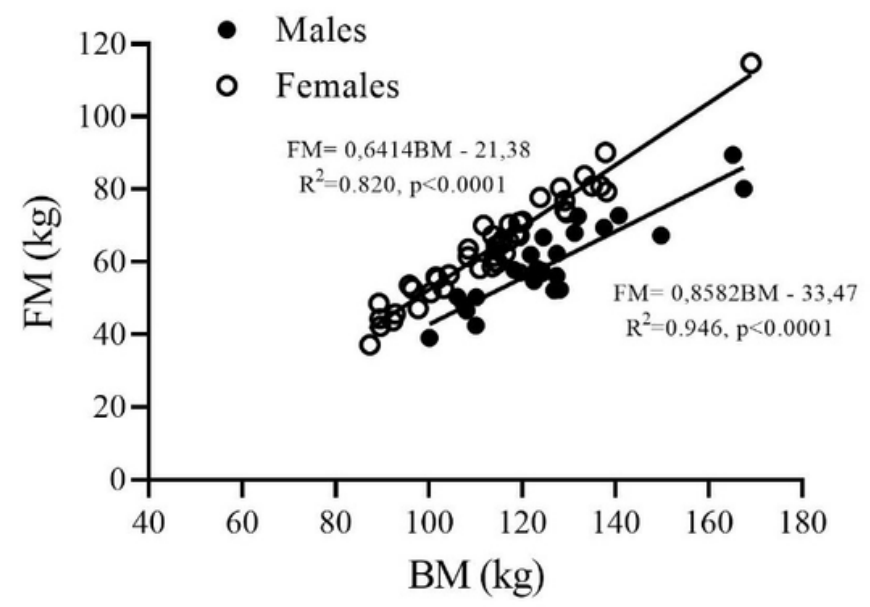

T21

\section{B}

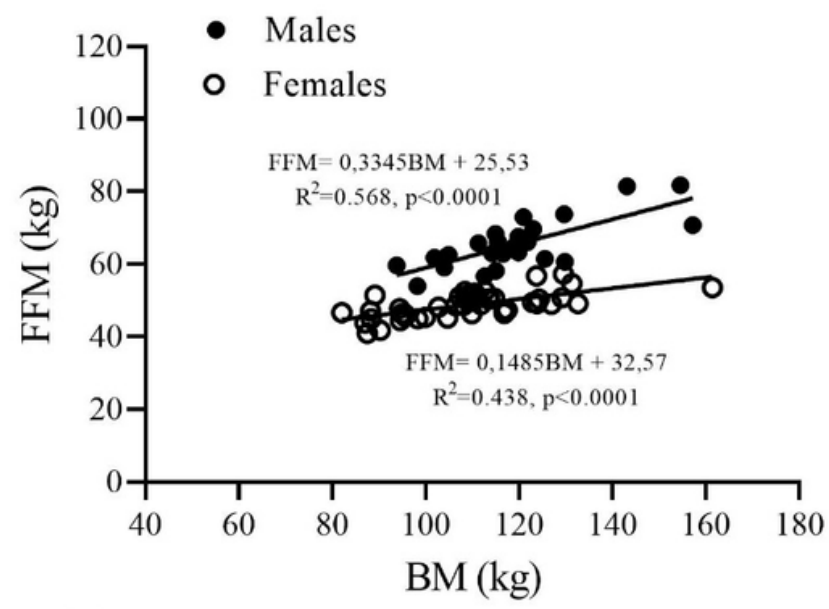

\section{D}

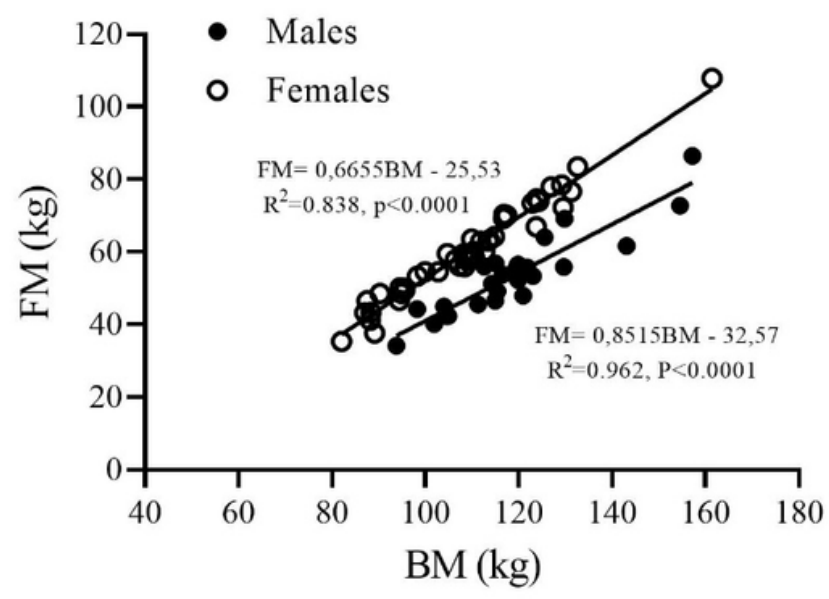

Figure 2

Fat free mass (FFM, panel A and B) and fat mass (FM, panel C and D) are plotted as a function of body mass (BM) in adult obese males (closed symbols) and females (open symbols) before (T0) and after (T21) of the 3-week BWRP. 